\title{
Candida Administration Worsens Neutrophil Extracellular Traps in Renal Ischemia Reperfusion Injury Mice: An Impact of Gut Fungi on Acute Kidney Injury
}

\author{
Supichcha Saithong ${ }^{a, b}$ Wilasinee Saisorn ${ }^{a, b}$ Cong Phi Dang ${ }^{a, b}$ \\ Peerapat Visitchanakun ${ }^{a, b}$ Direkrit Chiewchengchol ${ }^{a, b}$ \\ Asada Leelahavanichkula, b, c \\ aDepartment of Microbiology, Faculty of Medicine, Chulalongkorn University, Bangkok, Thailand; \\ bTranslational Research in Inflammation and Immunology Research Unit (TRIRU), Department of Microbiology, \\ Chulalongkorn University, Bangkok, Thailand; 'Division of Nephrology, Department of Medicine, Faculty of \\ Medicine, Chulalongkorn University, Bangkok, Thailand
}

\section{Keywords}

Neutrophil extracellular traps $\cdot$ Renal ischemia reperfusion injury · Lipopolysaccharide · Gut fungi · Beta-glucan

\section{Abstract \\ Because of gut-barrier defect (gut-leakage) after acute kid- ney injury (AKI) and higher abundance of Candida albicans in human intestines compared with mouse guts, Candida ad- ministration in renal ischemia reperfusion injury (I/R) mice possibly more closely resemble patients with AKI than non- Candida model. Fungi in feces were detectable only in mice with Candida administration. Candida renal-I/R mice, when compared with non-Candida $\mathrm{I} / \mathrm{R}$, demonstrated more pro- found injuries, including (i) gut-leakage; FITC-dextran assay and serum ( $1 \rightarrow 3$ )- $\beta$-D-glucan (BG), (ii) systemic inflammation (serum cytokines), and (iii) neutrophil extracellular traps (NETs); gene expression of peptidyl arginase 4 (PAD4) and IL- $1 \beta$, nuclear morphology staining by 4 ,6-diamidino-2-phe- nylindole (DAPI) and co-staining of myeloperoxidase (MPO) with neutrophil elastase (NE) in peripheral blood neutro- phils. Although renal excretory function (serum creatinine)}

karger@karger.com www.karger.com/jin

Karger"

BOPEN ACCESS
(C) 2022 The Author(s)

Published by S. Karger AG, Basel

This is an Open Access article licensed under the Creative Commons Attribution-NonCommercial-4.0 International License (CC BY-NC) (http://www.karger.com/Services/OpenAccessLicense), applicable to the online version of the article only. Usage and distribution for commercial purposes requires written permission. and renal histology score were nondifferent between renalI/R mice with and without Candida, prominent renal NETs (PAD4 and IL-1 $\beta$ expression with MPO and NE co-staining) was demonstrated in Candida renal-I/R mice. Additionally, neutrophil activation by lipopolysaccharide (LPS) plus BG $(\mathrm{LPS}+\mathrm{BG}$ ), when compared with LPS alone, caused (i) NETs formation; dsDNA, DAPI-stained nuclear morphology and MPO with NE co-staining, (ii) inflammatory responses; Spleen tyrosine kinase (Syk) and NFKB expression, and (iii) reduced cell energy status (maximal respiratory capacity using extracellular flux analysis). Also, LPS + BG-activated NETs formation was inhibited by a dectin-1 inhibitor, supporting an impact of BG signaling. In conclusion, Candida-renal I/R demonstrated more prominent serum BG and LPS from gut translocation that increased systemic inflammation and NETs through TLR-4 and dectin-1 activation. The influence of gut fungi in AKI should be concerned.

(c) 2022 The Author(s)

Published by S. Karger AG, Basel

Supichcha Saithong and Wilasinee Saisorn contributed equally.
Correspondence to:

Direkrit Chiewchengchol, cdirekrit@live.com

Asada Leelahavanichkul, aleelahavanit@gmail.com 


\section{Introduction}

The cross talk between gastrointestinal (GI) tract and other systems, partly through gut microbiota and immune responses [1], referred to as gut-renal axis [2] is well-known. One of the intestinal influences against other organs is through the translocation of pathogen-associated molecular patterns (PAMPs) from Gram-negative bacteria and fungi, the most and second-highest abundant organisms in feces, respectively [2]. Although gramnegative bacteria are an important source of lipopolysaccharide (LPS), an endogenous toxin, in gut of both human and mice, the abundance of fungi, particularly Candida albicans which are the source of $(1 \rightarrow 3)-\beta-D-$ glucan (BG) in gut, of mouse GI tract, is less than in human $[3,4]$. As such, fungi in mouse feces could not be detectable by culture different from human stool $[3,4]$. Due to the difference, several mouse models, especially the models with possible GI cross talk, might not appropriately represent the human conditions and Candida administration in mice might make the models resemble more that of human conditions [5-7]. In parallel, acute kidney injury (AKI), a common health care problem worldwide, is mainly caused by ischemia and renal ischemia reperfusion injury (I/R) model is a common representative model of AKI $[8,9]$. Because of the well-established gut-renal axis [2], uremia in regular mice might be different from uremia in mice with the presence of Candida in gut. Accordingly, Candida administration worsens uremia-induced gut permeability defect in bilateral nephrectomy mice [10], partly through an impact of BG on macrophages [7]. However, macrophages are not only the immune cells responsible for uremia-induced inflammation and uremia from bilateral nephrectomy, without an influence of the injured kidney, might be different from the patients with AKI.

As such, renal ischemia induces neutrophil accumulation, as a response to the injury [11-13], and renal cell apoptosis (and necrosis) causes the distance impact on several organs $[14,15]$. Interestingly, neutrophil extracellular traps (NETs) the networks of extracellular DNA fibers, of accumulated neutrophils in kidney is one of the important innate immune responses against renal-I/ $\mathrm{R}$ injury [16]. The program cell death (apoptosis and necrosis) in renal parenchymal cells also induces NETs in other nonrenal organs [16]. Additionally, NETosis (cell death after NETs formation) is inducible by either infection or noninfectious conditions [17] through peptidylarginine deiminase 4 (PAD4) activation [18]. The NETosis pathways, both by NADPH oxidase 2 (NOX2)-depen- dent and NOX2-independent pathways, enhance exposure of nuclear contents [19], including dsDNA (free dsDNA), that is recognized as DAMPs by innate immune cells and increase pro-inflammatory status [20]. Not only apoptosis and necrosis of renal cells, but also cell death of the accumulated neutrophils also further enhance severity of renal I/R [16]. In AKI, NETosis is not only caused by DAMPs from renal cells [17] but also inducible by several PAMPs (LPS and BG) from uremia-induced gut permeability defect [21]. However, gut translocation of BG might be more prominent in humans than mice because of the prominent presence of Candida in human gut [ 3 , 4]. Interestingly, both LPS and BG activate NETosis through TLR-4 and dectin-1, respectively [21], with a possible additive effect by the co-stimulation of LPS and BG through TLR-4 and dectin-1 cross-link [22, 23] with some important downstream signals, including spleen tyrosine kinase (Syk) and nuclear factor kappa-B (NFkB) $[24,25]$. Because of (i) the presence of LPS and BG in serum from uremia-induced gut permeability defect [10], (ii) NETs induction by both LPS and BG [21], and (iii) less fungal abundance in mouse guts than human intestines $[3,4]$, NETs formation was explored in renal I/R mice with Candida administration and the stimulations by LPS and BG in peripheral blood neutrophils from healthy volunteers.

\section{Materials and Methods}

\section{Renal I/R Model}

The animal study protocol, following the National Institutes of Health (NIH, Bethesda, MD, USA), was approved by the Faculty of Medicine, Chulalongkorn University, Bangkok, Thailand, and 8-week-old male mice were purchased from Nomura Siam International (Pathumwan, Bangkok, Thailand). To explore impact of gut fungi in acute uremia, Candida albicans from the American Type Culture Collection (ATCC; 90028) (Fisher Scientific, Waltham, MA, USA) were administered. As such, C. albicans was cultured overnight on Sabouraud dextrose broth (Oxoid, Hampshire, UK) at $35^{\circ} \mathrm{C}$ for $48 \mathrm{~h}$ before enumeration using a hemocytometer, and C. albicans at $1 \times 10^{6} \mathrm{CFU}$ in a $0.5 \mathrm{~mL}$ phosphate buffer solution (PBS) or PBS alone was orally administered daily for 3 days before surgery. Then, renal I/R was performed at $6 \mathrm{~h}$ after the last dose of fungi by abdominal incision according to a previous publication [9]. In brief, bilateral renal arteries were clamped for $35 \mathrm{~min}$ through abdominal incision under ketamine anesthesia on a $37^{\circ} \mathrm{C}$ heated operation table. In sham surgery, both renal arteries were only identified before closing the abdominal wall. Tramadol, $20 \mathrm{mg} / \mathrm{kg}$ diluted in $0.5 \mathrm{~mL}$ normal saline (NSS) was administered subcutaneously after surgery and at $6 \mathrm{~h}$ post-I/R. Mice were sacrificed at $24 \mathrm{~h}$ after I/R under isoflurane anesthesia for sample collection. Serum was kept at $-80^{\circ} \mathrm{C}$ until analysis and organs were pro- 
cessed in $10 \%$ formalin or Tissue-Tek O.C.T. Compound (Sakura Finetek, Torrance, CA, USA) or snap frozen and separately stored at $-80^{\circ} \mathrm{C}$.

\section{Mouse Serum and Fecal Sample Analysis}

To explore fungi in feces, mouse feces were collected using metabolic cages (Hatteras Instruments, Cary, NC, USA). Then, fecal samples were suspended with $\mathrm{PBS}$ at a ratio of $100 \mathrm{mg}$ feces per 1 $\mathrm{mL}$ PBS, serially diluted onto SDA (Oxoid), and incubated at $35^{\circ} \mathrm{C}$ for $72 \mathrm{~h}$ before colony enumeration of fungi. Renal injury was determined by blood urea nitrogen and serum creatinine (Scr) using QuantiChrom Urea-assay (DIUR-500) and Creatinine-Assay (DICT-500) (BioAssay, Hayward, CA, USA), respectively. Proteinuria was calculated by spot urine protein creatinine index with the equation; urine protein creatinine index = urine protein $(\mathrm{mg}) /$ urine creatinine $(\mathrm{mg} / \mathrm{dL})$. Urine protein and creatinine were measured by Bradford Bio-Rad Protein Assay (Bio-Rad, Hercules, CA, USA) and QuantiChrom Creatinine-Assay (DICT-500) (BioAssay), respectively. Serum pro-inflammatory cytokines (TNF- $\alpha$, IL-6, IL10 , and IL-1 $\beta$ ) and liver enzyme (alanine transaminase) were measured by enzyme-linked immunosorbent assay (Invitrogen, Waltham, MA, USA) and EnzyChrom alanine transaminase assay (EALT-100; BioAssay), respectively. For detection of NETs in peripheral blood neutrophils [21], mouse neutrophils were isolated using Polymorph-prep (Alere Technologies AS, Oslo, Norway), according to the manufacturer's instructions and neutrophils were resuspended in RPMI 1640 media. Only the samples with $>95 \%$ neutrophils purity by Wright's stains were further used. Then, NETs formation was determined by (i) serum dsDNA using Quant-

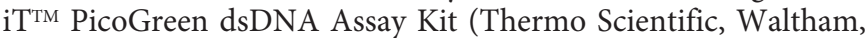
MA, USA), (ii) nuclear morphology of neutrophils (branching of the nuclei) using a blue-fluorescent DNA stain 4',6-diamidino2-phenylindole (DAPI) (Sigma-Aldrich, St. Louis, MO, USA) and (iii) the co-staining of myeloperoxidase (MPO) and neutrophil elastase (NE) (Abcam, Cambridge, MA, USA) according to the previous publication [21]. The fluorescent intensities were analyzed with ZEISS LSM 800 (Carl Zeiss, Jena, Germany).

\section{Gut Integrity Determination}

Gut permeability defect (gut leakage) was determined by the detection of nonabsorbable carbohydrate (fluorescein isothiocyanatedextran; FITC-dextran) in serum after an oral administration and the spontaneous serum elevation of gut microbial molecules, including LPS (endotoxin) and BG, as previously published [10]. Accordingly, FITC-dextran (molecular weight $4.4 \mathrm{kDa}$; Sigma-Aldrich) at $25 \mathrm{mg}$ / $\mathrm{mL}$ in $0.25 \mathrm{~mL}$ PBS was orally administered at $3 \mathrm{~h}$ before detecting FITC-dextran in serum by fluorospectrometry (Thermo Scientific, Wilmington, DE, USA). In parallel, serum LPS and BG were measured using HEK-blue LPS detection assay (InvivoGen, San Diego, CA, USA) and Fungitell (Associates of Cape Cod, Falmouth, MA, USA). The values of LPS $<0.01 \mathrm{EU} / \mathrm{mL}$ and $\mathrm{BG}<7.8 \mathrm{pg} / \mathrm{mL}$ were recorded as 0 due to the limitation of the standard curves.

\section{Polymerase Chain Reaction}

PAD4 and interleukin- 1 beta $(I L-1 \beta)$, the NETs formation associated genes, were determined from mouse samples using realtime polymerase chain reaction by a standard protocol [21] with the following primers (for mouse genes); PAD4 forward $5^{\prime}$-ACAGGTGAAAGCAGCCAGC-3' ${ }^{\prime}$, reverse 5'-AGTGATGTAGATCAGGGCTTGG-3'; IL-1 $\beta$ forward 5'-GAAATGCCACCTTTTGA-
CAGTG-3' ${ }^{\prime}$, reverse $5^{\prime}$-TGGATGCTCTCATCAGGACAG- ${ }^{\prime}$; Beta-actin ( $\beta$-actin, an endogenous housekeeping gene) forward $5^{\prime}$-CGGTTCCGATGCCCTGAGGCTCTT-3', reverse $5^{\prime}$-CGTCACACTTCATGATGGAATTGA- $3^{\prime}$. Also, other primers were used for detection of human genes as follows: Syk forward $5^{\prime}$-TGGGAAGCATTCTCCTATGG-3' , reverse $5^{\prime}$-CCACATCGTATGTCCAGCAC- $3^{\prime}$; nuclear factor kappa B $(N F \kappa B)$ forward $5^{\prime}$-GCGAGAGGAGCACAGATACC-3' ${ }^{\prime}$, reverse $5^{\prime}$-CTGATAGCCTGCTCCAGGTC-3; and $\beta$-actin forward $5^{\prime}$-GGACTTCGAGCAAGAGATGG-3' ${ }^{\prime}$, reverse $5^{\prime}$-AGCACTGTGTTGGCGTACAG$3^{\prime}$. The samples were prepared by an RNA-easy mini kit (Qiagen, Hilden, Germany), nanodrop 100 spectrophotometer, high-capacity cDNA reverse transcription, and SYBR Green PCR Master Mix for quantitative real-time polymerase chain reaction with QuantStudio6 Flex Real-time PCR System (Thermo Scientific). The results were demonstrated in relative quantitation of the comparative threshold method $\left(2^{-\Delta \Delta \mathrm{Ct}}\right)$ as normalized by $\beta$-actin.

\section{Histological Analysis and Immunofluorescent Imaging}

The semi-quantitative evaluation of renal histology on paraffin-embedded slides was performed after $10 \%$ neutral buffered formalin fixation, followed by hematoxylin and eosin and periodic acid-schiff staining at $\times 200$ magnification in 10 randomly selected fields for each animal [26-28]. Renal injury was defined as tubular epithelial swelling, loss of brush border, vacuolar degeneration, necrotic tubules, cast formation, and desquamation using the following scoring method: 0 , area of damage $<5 \%$; area of damage $5-10 \%$; 2 , area of damage $10-25 \%$; 3 , area of damage $25-50 \%$; and 4 , area of damage $>50 \%$. In parallel, immunofluorescent histological analysis and in peripheral blood neutrophils were performed following previous publications [29-31]. In brief, the internal organs were prepared in Tissue-Tek O.C.T. Compound (Sakura Finetek) and stained for NETs using the co-staining of MPO and NE (Abcam) with DAPI color (Sigma-Aldrich). The fluorescent intensities were analyzed with ZEISS LSM 800 (Carl Zeiss).

\section{The in vitro Experiments on Neutrophils and Dectin-1 \\ Inhibitor}

An impact of BG, a main cell wall component of fungi on NETosis was tested in human neutrophils. As such, heparinized blood was collected from healthy donors under an approved protocol by the Ethical Institutional Review Board, Faculty of Medicine, Chulalongkorn University, according to the Declaration of Helsinki, with written informed consent. Neutrophils were isolated by density centrifugation with Polymorphprep ${ }^{\mathrm{TM}}$ (Axis-Shield, Oslo, Norway) and were resuspended in RPMI 1640 supplemented with $10 \%$ fetal bovine serum. Human neutrophils (at $1 \times 10^{4}$ cells) were placed onto Poly-L-Lysine (Sigma-Aldrich) coated glass coverslips, incubated at $37^{\circ} \mathrm{C}, 5 \% \mathrm{CO}_{2}$ for $1 \mathrm{~h}$ with $\mathrm{BG}$ using whole glucan particle (WGP) (the purified BG from Saccharomyces cerevisiae) (Biothera, Eagan, MN, USA), at $10 \mu \mathrm{g} / \mathrm{mL}$ with or without LPS (Escherichia coli 026: B6) (Sigma-Aldrich) at $10 \mu \mathrm{g} / \mathrm{mL}[10,21,29,32-$ 36]. After $2 \mathrm{~h}$ of incubation, the coverslips were fixed with $4 \%$ formaldehyde, blocked with tris buffered saline in $2 \%$ bovine serum albumin (Sigma-Aldrich) and permeabilized by tris buffered saline with $0.05 \%$ Tween 20 (Sigma-Aldrich). Then, NETs formation was detected by nuclear morphology DAPI staining, the co-staining of MPO and NE fluorescent colors as previously described and free dsDNA in supernatant. For the detection of free dsDNA, stimulated neutrophils were incubated with $0.1 \mathrm{M} \mathrm{CaCl}_{2}$ and 0.5 unit (U) 
of micrococcal nuclease (Sigma-Aldrich) at $37^{\circ} \mathrm{C}, 5 \% \mathrm{CO}_{2}$ for 10 min before stopping the nuclease reaction by $0.5 \mathrm{M}$ ethylenediaminetetraacetic acid. Then, the supernatant was collected and QuantiT ${ }^{\mathrm{TM}}$ PicoGreen reagent (Thermo Fisher Scientific) was added to measure dsDNA by incubating aqueous working solution in the sample for $5 \mathrm{~min}$ at room temperature (protected from light). The amount of dsDNA in the mixture was measured at $480 \mathrm{~nm}$ excitation (520 nm emission) on a fluorescent microplate reader. Furthermore, dectin-1 inhibitor (soluble glucan, a competitive dectin-1 binding agent) (InvivoGen) was used to explore the mechanistic pathway of LPS with BG in FcgRIIb ${ }^{-1-}$ neutrophils. Then, LPS (LPS Escherichia coli 026: B6) (Sigma-Aldrich) at $10 \mu \mathrm{g} / \mathrm{mL}$ plus BG (WGP) (Biothera) at $10 \mu \mathrm{g} / \mathrm{mL}$ was incubated with human neutrophils (at $1 \times 10^{4}$ cells) for $2 \mathrm{~h}$ together with dectin- 1 inhibitor at 25 $\mathrm{mg} / \mathrm{mL}$ or PBS (as a control) before determination of NETs using supernatant dsDNA, PAD4 expression, and NETs formation by MPO plus NE co-staining as previously mentioned.

\section{Extracellular Flux Analysis}

Because the enhanced cell energy might be responsible for the increased cell activity, the stimulated human neutrophils by LPS with or without BG and control media were analyzed by Seahorse XF Analyzers (Agilent, Santa Clara, CA, USA) as previously published [28, 37]. The energy metabolism profiles are estimated by glycolysis and mitochondrial oxidative phosphorylation based on extracellular acidification rate and oxygen consumption rate, respectively, on neutrophils. Due to the short life span of neutrophils, LPS (Escherichia coli 026: B6) (Sigma-Aldrich) at $100 \mu \mathrm{g} / \mathrm{mL}$ with or without BG (WGP) (Biothera) at $100 \mu \mathrm{g} / \mathrm{mL}$ were added in neutrophils $\left(1 \times 10^{4}\right.$ cells per well) right before incubation with the standard reagents of Seahorse XF analysis. For mitochondrial stress test, assays were performed in Seahorse XF DMEM medium (Agilent Technologies) supplemented with $2 \mathrm{mM}$ Seahorse XF L-glutamine, $1 \mathrm{~mm}$ pyruvate, and $10 \mathrm{~mm}$ XF glucose. Then, cells were sequentially incubated by oligomycin, carbonyl cyanide 4-(trifluoromethoxy) phenylhydrazone, and rotenone/antimycin A (final concentration of $1.5 \mu \mathrm{M}, 1 \mu \mathrm{M}$, and $0.5 \mu \mathrm{M}$, respectively). In parallel, glycolysis stress tests were calculated from the mitochondrial stress test using the wave program of Seahorse XF Analyzers (Agilent). Notably, the results in Seahorse analysis were normalized by applying the total protein abundance in the wave program to measure all parameters.

\section{Statistical Analysis}

Statistical differences among groups were examined using the unpaired Student's $t$ test or one-way analysis of variance with Tukey's comparison test for the analysis of experiments with two groups or more than two groups, respectively. The data are presented as the mean \pm SE. SPSS 11.5 software (SPSS, Chicago, IL, USA) was used for all statistical analyses.

\section{Results}

Candida administration enhanced gut leakage, gut translocation of BG and systemic inflammation in renal $I / R$, partly through the reduced cell energy status that facilitated NETs.

\section{Candida Administration Enhanced Systemic}

Inflammation and Neutrophil Extracellular Traps in

Renal I/R Mice

Culture for fecal fungi was negative in all group without Candida administration and the abundance of fungi in feces was similar between sham and renal I/ $\mathrm{R}$ with fecal gavage (Fig. 1a). Because the peak of injury in renal I/R injury was at $24 \mathrm{~h}$ of the model as previously published [8], several parameters were determined at $24 \mathrm{~h}$ post-I/R. Accordingly, renal function (blood urea nitrogen and Scr), renal histology, and liver enzyme were not different between renal I/R with or without fungal gavage but proteinuria and gut permeability defect (FITC-dextran assay and serum BG but not endotoxemia) were more prominent in renal I/R with Candida compared with I/R injury alone (Fig. 1b-j). Notably, proteinuria at $24 \mathrm{~h}$ after I/R demonstrates an initial consequence of renal ischemiainduced podocyte damage, despite normal renal excretory function (blood urea nitrogen and Scr) $[38,39]$. Despite the increase in serum BG, renal I/R with Candida had similar serum LPS compared to I/R alone (Fig. 1i, j). To demonstrate an impact of neutrophil accumulation in kidneys at $24 \mathrm{~h}$ post renal-I/R using the hematoxylin and eosin-stained renal sections, neutrophils in sediments (online suppl. Fig. 1, left; for all online suppl. material, see www.karger.com/doi/10.1159/000521633), tubulointerstitial area and glomeruli (online suppl. Fig. 1 right) of I/R with PBS (which were not different from Candida-administered I/R) were demonstrated. However, gut translocation of LPS and BG in renal I/R mice with or without Candida were severe enough to enhance systemic inflammation (serum cytokines; TNF- $\alpha$, IL-6, IL-10, and IL- $1 \beta$ ) (Fig. 2a-c) and NETosis (cell death from NETs formation); serum dsDNA, PAD4 expression and neutrophils

Fig. 1. Characteristics of renal I/R with Candida administration (I/R fungi) or I/R PBS or sham with Candida administration (Sham fungi) at $24 \mathrm{~h}$ after surgery as determined by abundance of fecal fungi (a), renal injury; BUN and $\mathrm{Scr}(\mathbf{b}, \mathbf{c})$, the representative pictures in H\&E and PAS (original magnification, $\times 200$ ) with the histological score (d, e), proteinuria (protein creatinine index; UPCI) (f), liver injury (serum ALT) (g), and gut leakage, serum FITC-dextran assay, endotoxemia, and serum BG (h-j), are demonstrated ( $n=6-7 /$ time-point). Notably, the sham group without Candida administration is not demonstrated due to the similarity to sham with Candida (normal values in all parameters). BUN, blood urea nitrogen; H\&E, hematoxylin and eosin.

(For figure see next page.)

Candida Worsens Neutrophil

Extracellular Traps in Renal I/R Injury
J Innate Immun 2022;14:502-517

DOI: $10.1159 / 000521633$ 


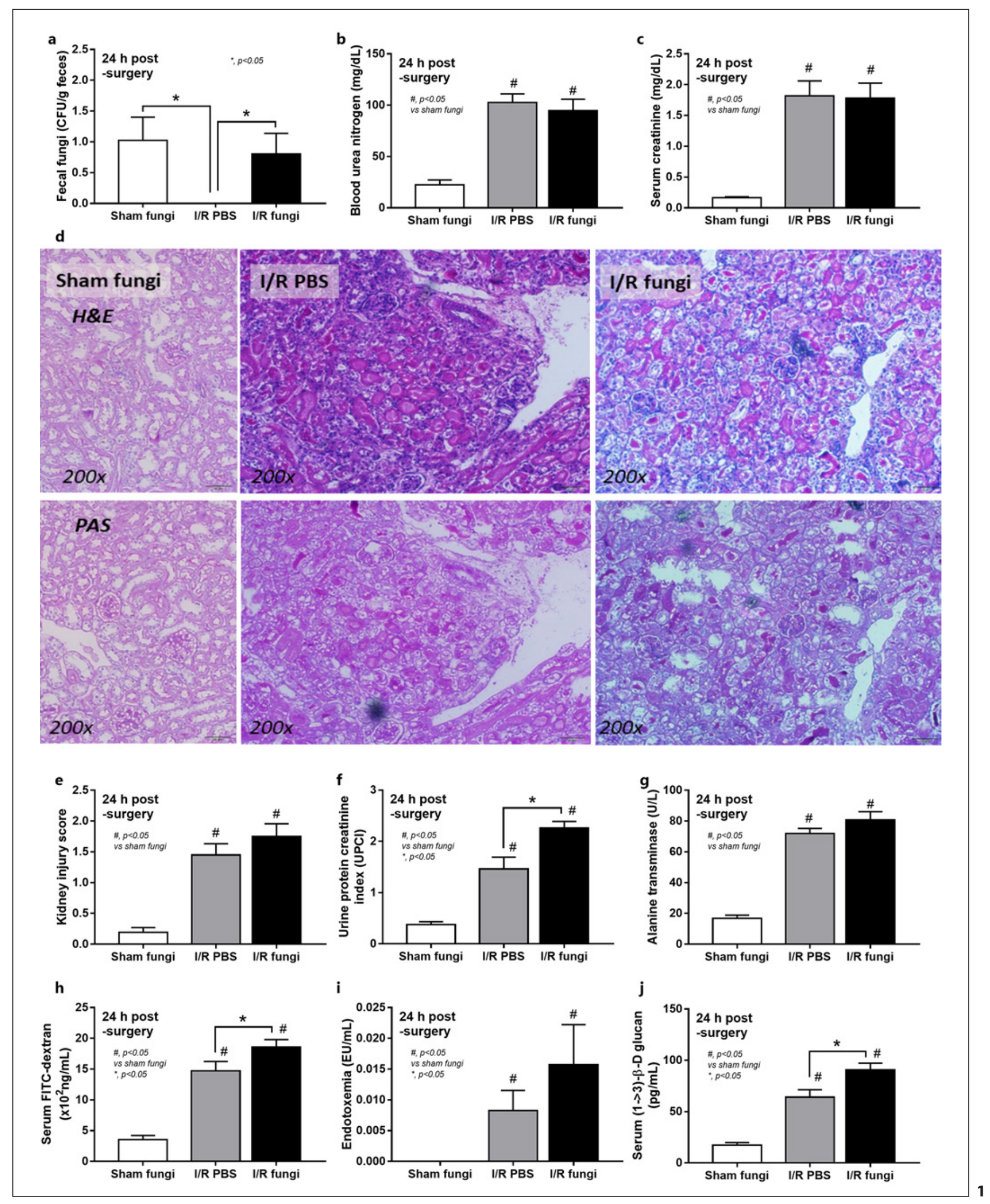




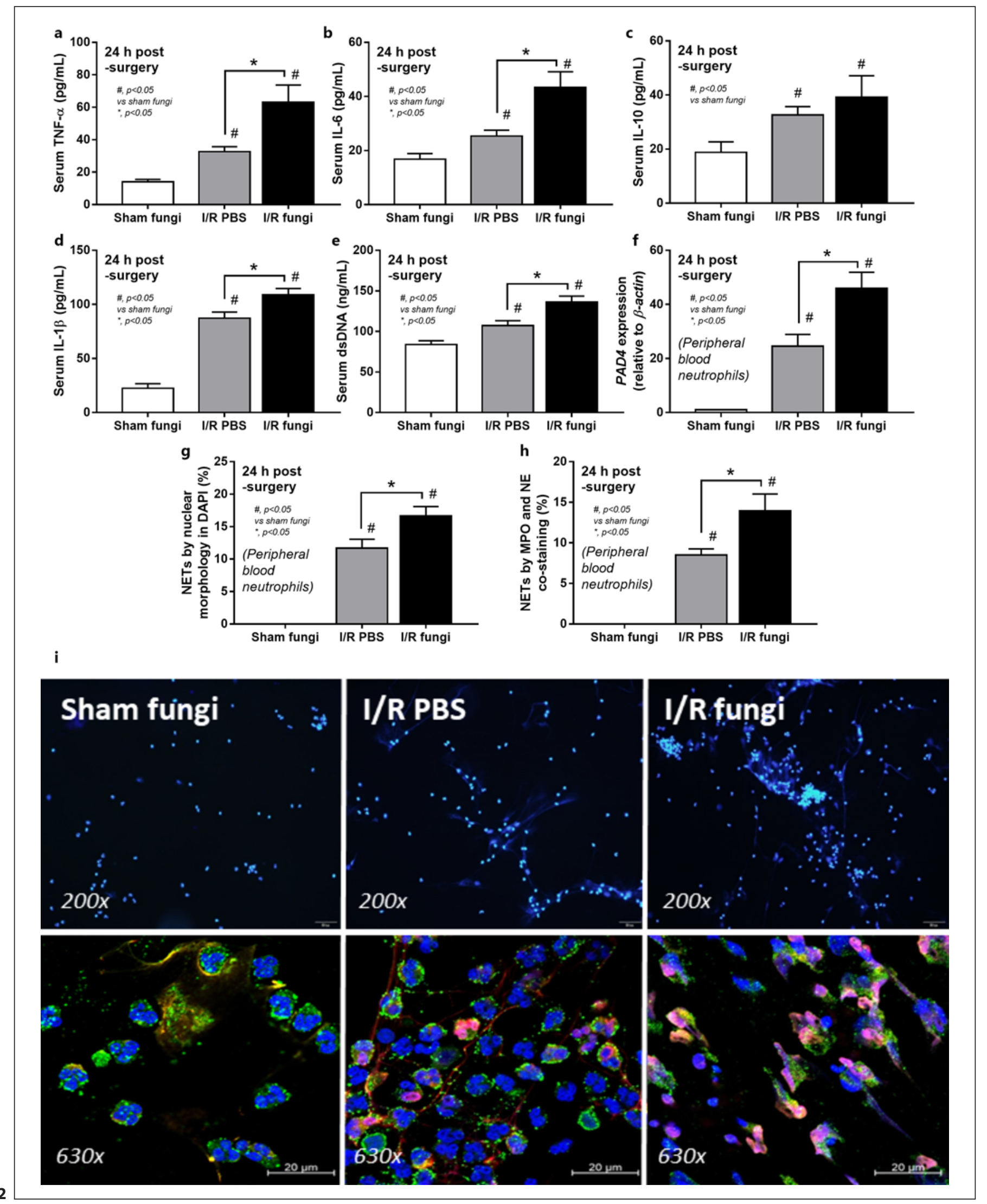

(For legend see next page.)

Candida Worsens Neutrophil

Extracellular Traps in Renal I/R Injury
J Innate Immun 2022;14:502-517

DOI: $10.1159 / 000521633$

507 
staining (nuclear morphology by DAPI, co-staining of MPO with NE) (Fig. 2a-i). Nevertheless, the systemic inflammation and NETs formation in blood neutrophils were more prominent in Candida-administered I/R mice
(Fig. 2a-i). Likewise, NETs formation in kidneys, as determined by expression of PAD4 and $I L-1 \beta$ with immunofluorescent of MPO and NE co-staining, were detectable in both renal I/R mice with and without Candida but

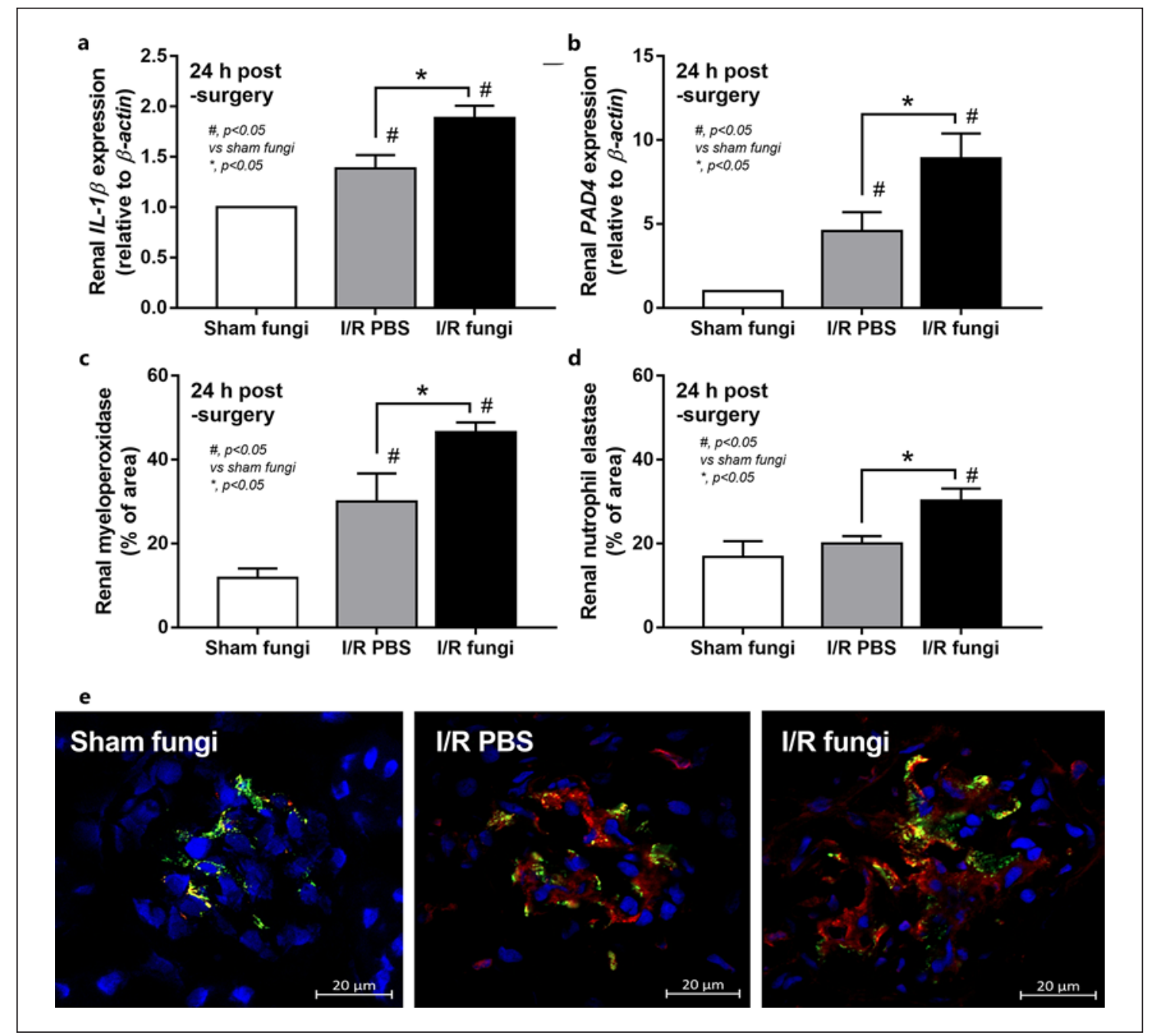

Fig. 3. Characteristics of renal I/R with Candida administration (I/R fungi) or (I/R PBS) or sham with Candida administration (Sham fungi) at $24 \mathrm{~h}$ after surgery as indicated by NETs in renal tissue as determined by expression of $I L-1 \beta$ and PAD4 (a, b) and the co-staining of MPO and NE at $24 \mathrm{~h}$ post-I/R with the representative immunofluorescent pictures of MPO (red), NE (green), and DAPI ( blue nuclear staining) (original magnification, $\times 630)(\mathbf{c}-\mathbf{e})$ are demonstrated ( $n=6-7 /$ group). Notably, the sham group without Candida administration is not demonstrated due to the similarity to sham with Candida (normal values in all parameters).

Fig. 2. Characteristics of renal I/R with Candida administration (I/R fungi) or I/R PBS or sham with Candida administration (Sham fungi) at $24 \mathrm{~h}$ after surgery as determined by systemic inflammatory responses as indicated by serum cytokines (TNF- $\alpha$, IL-6, IL-10, and IL-1 $\beta$ ) (a-d) and NETs formation as evaluated by serum dsDNA (e) and in peripheral blood neutrophils using gene expression of PAD4 (f), cell morphology in DAPI staining (blue color) $(\mathbf{g})$, co-staining of MPO and NE (h), with the representative pictures of DAPI staining (original magnification, $\times 200)(\mathbf{i}$, upper part) and immunofluorescence of MPO/NE (original magnification, $\times 630)(\mathbf{i}$, lower part) are demonstrated ( $n=6-7 /$ group). Notably, the sham group without Candida administration is not demonstrated due to the similarity to sham with Candida (normal values in all parameters). 


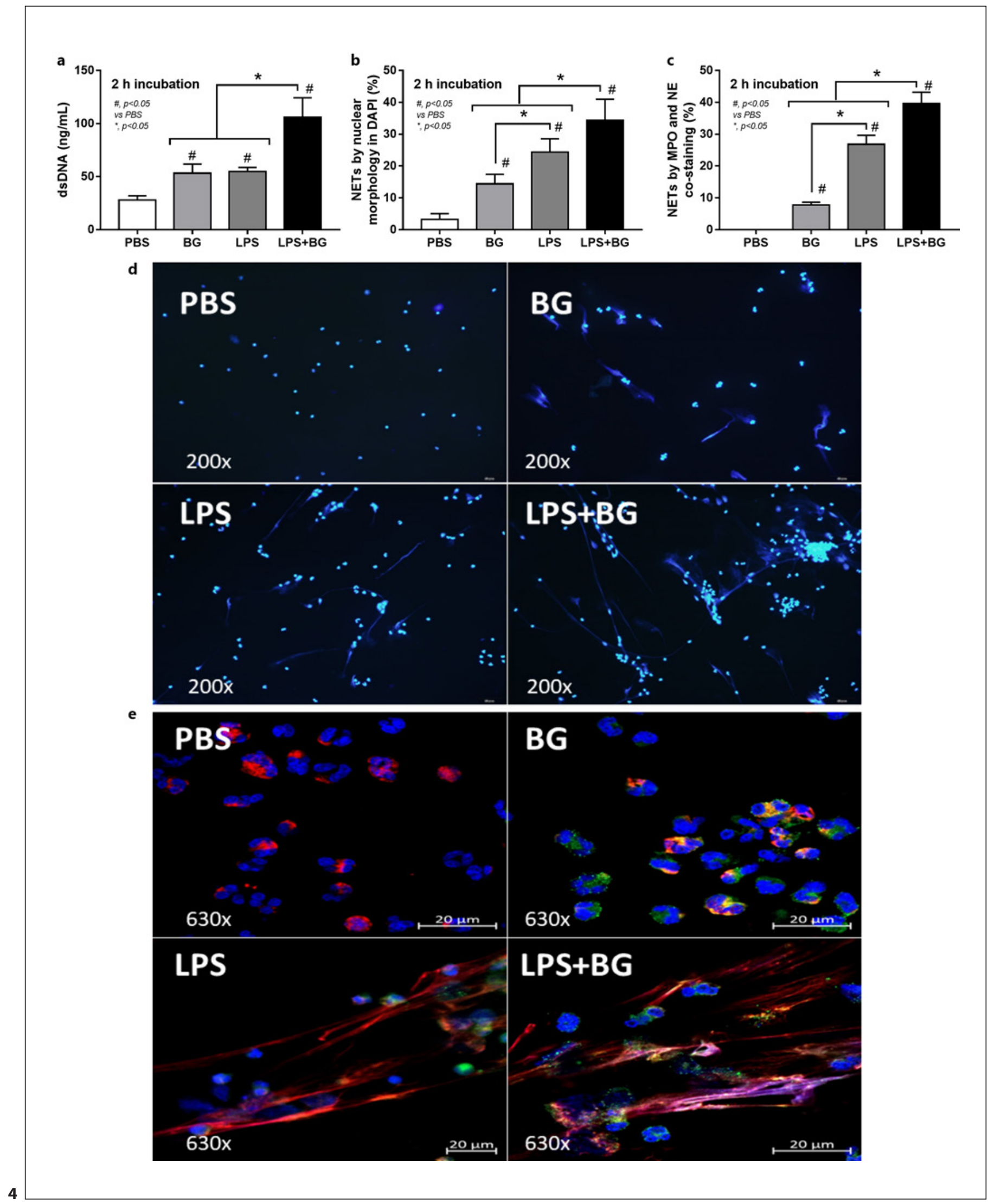

(For legend see next page.) 
more prominent in Candida I/R group (Fig. 3a-e). Notably, NETs formation could not be demonstrated in several internal organs (liver, kidney, and lung) at $6 \mathrm{~h}$ post$\mathrm{I} / \mathrm{R}$ (online suppl. Fig. 2 ) nor in the liver at $24 \mathrm{~h}$ post-I/R (online suppl. Fig. 3).
The Additive Effect of BG on LPS-Induced NETs

Possibly through Spleen Tyrosine Kinase Signaling and Cell Energy Alteration

Although DAMPs from necrotic renal cells could induce NETosis [40], PAMPs (both LPS and BG from ure-

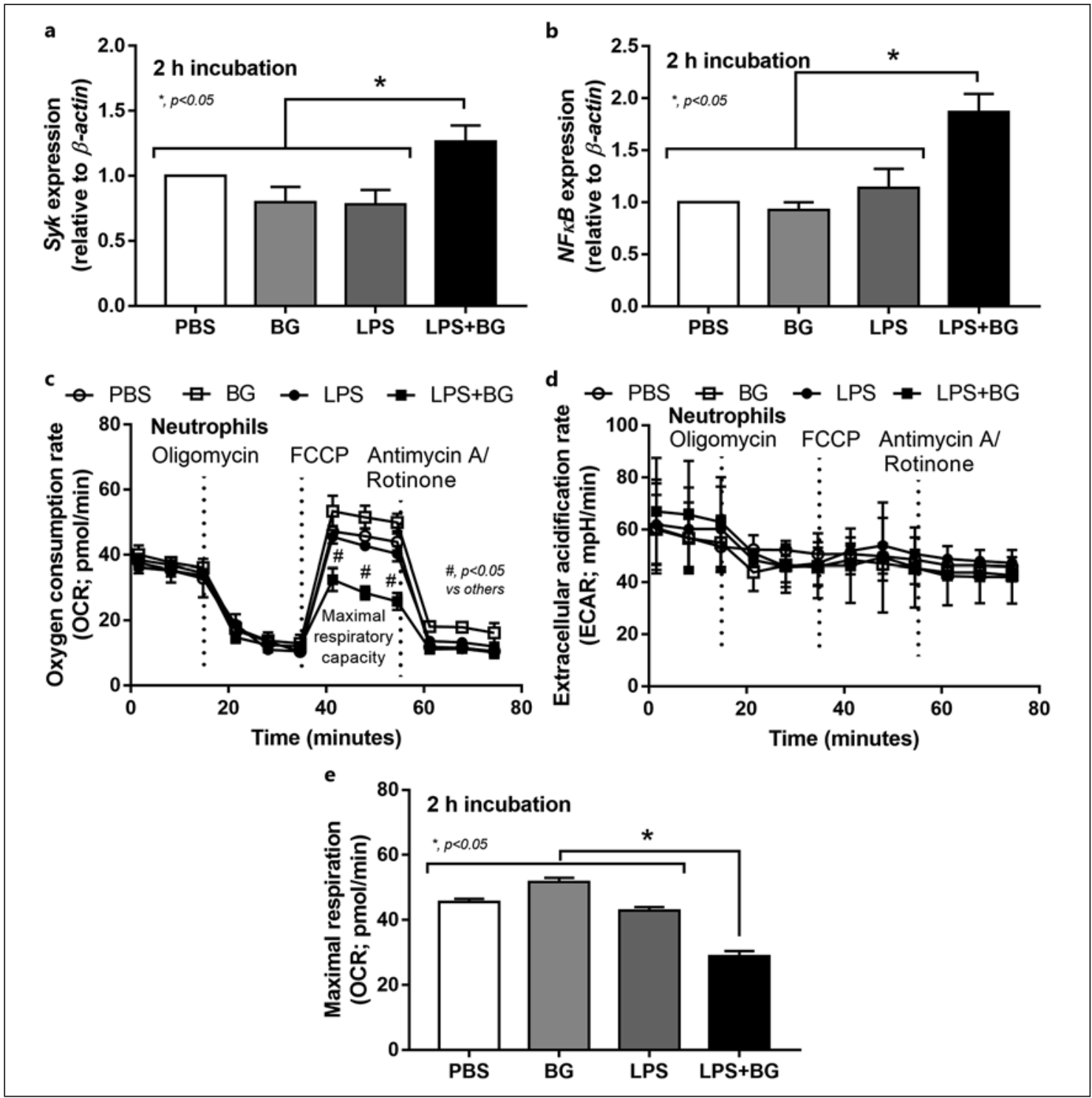

Fig. 5. Characteristics human neutrophils after activation by LPS with or without BG or control PBS at $2 \mathrm{~h}$ of the stimulation as evaluated by gene expression of $S y k$ and $N F \kappa B(\mathbf{a}, \mathbf{b})$ and the extracellular flux analysis as indicated by OCR (mitochondrial function), ECAR (glycolysis activity) and maximal respiration (from OCR curve) (c-e) are demonstrated (independent triplicated experiments were performed).

Fig. 4. Characteristics human neutrophils after activation by LPS with or without $(1 \rightarrow 3)$ - $\beta$-D-glucan $(B G)$ or control PBS at $2 \mathrm{~h}$ of the stimulation as evaluated by supernatant dsDNA (a), nuclear morphology after DAPI (blue nuclear staining) (b) and the co-staining of MPO and NE (c) with the representative immunofluorescent pictures of DAPI staining (d) and the staining of MPO and NE (e) are demonstrated (independent triplicated experiments were performed). 


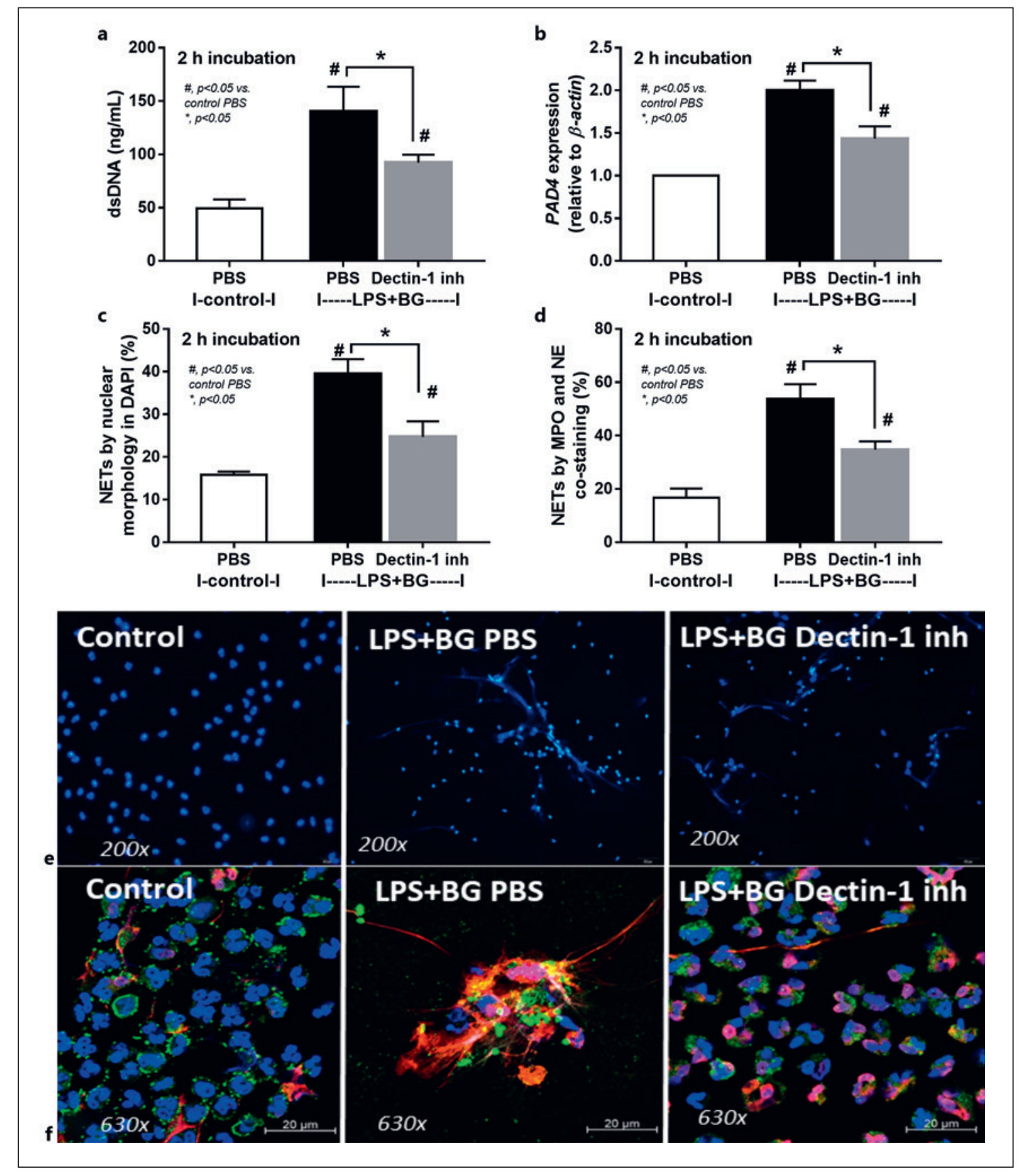

Fig. 6. Characteristics human neutrophils after activation by control PBS or LPS + BG with or without dectin-1 inhibitor at $2 \mathrm{~h}$ of the stimulation as evaluated by supernatant dsDNA (a), PAD4 expression (b), nuclear morphology after DAPI (blue nuclear staining) (c) and the co-staining of MPO and NE (d) with the representative immunofluorescent pictures of DAPI staining (e) and the co-staining of MPO and NE (f) are demonstrated (independent triplicated experiments were performed).

mia-induced gut translocation) could also induce NETs formation and the presence of both LPS and BG might have an additive effect on NETs. Indeed, LPS or BG, alone or in combination, facilitated NETs formation of human

Candida Worsens Neutrophil

Extracellular Traps in Renal I/R Injury neutrophils but NETosis from LPS + BG was more prominent than the activation by either LPS or BG alone as indicated by dsDNA, DAPI, and MPO-NE co-staining (Fig. 4a-d). Notably, NETs formation after LPS induction

J Innate Immun 2022;14:502-517 


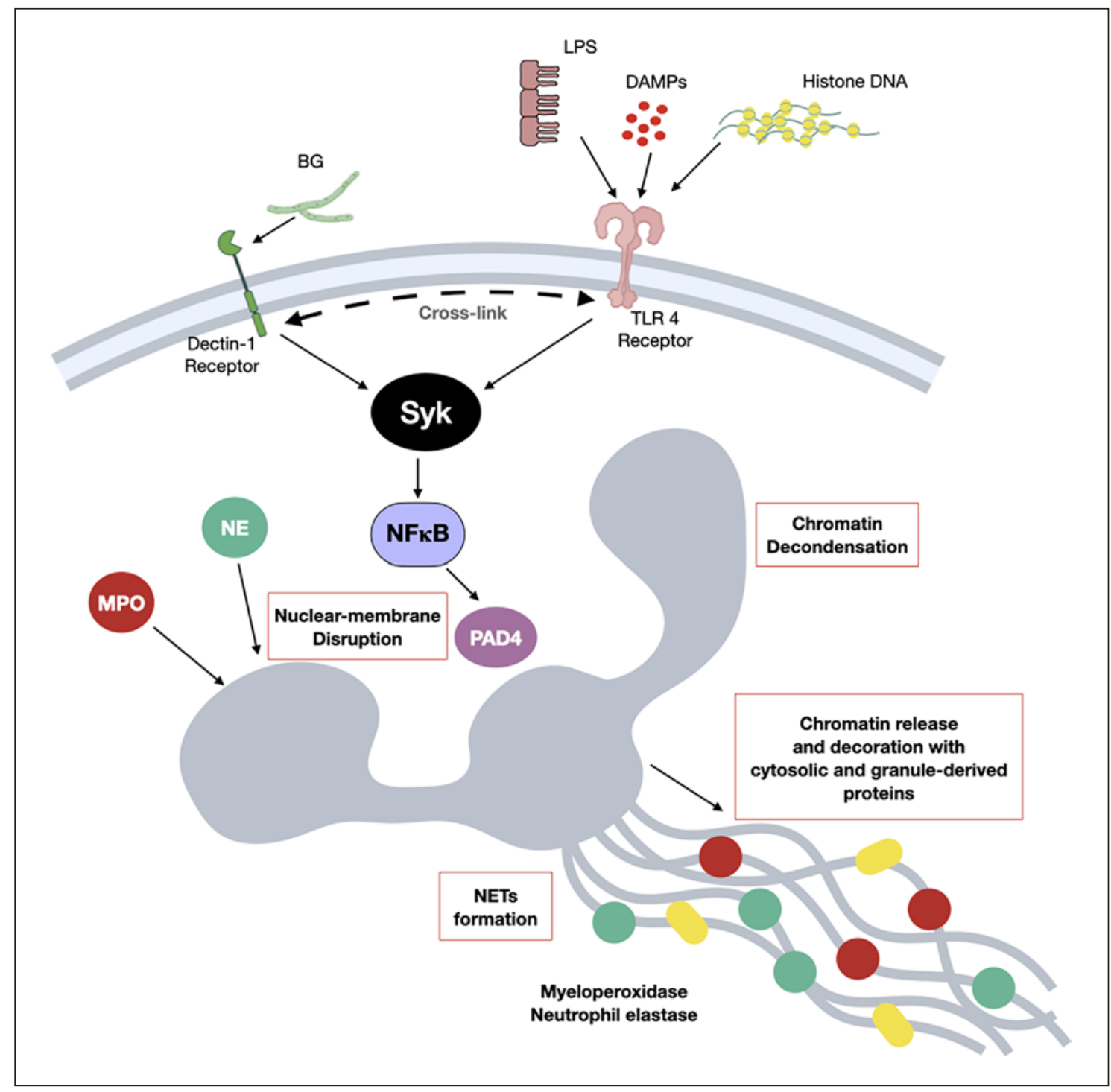

Fig. 7. A picture of the working hypothesis demonstrates NETs formation, nuclear membrane disruption, chromatin release and the activation of MPO and NE, from the possible cross talk between dectin-1 and TLR-4 through the common downstream signaling; Syk and NFkB, with PAD4 activation are demonstrated. While dectin- 1 is activated by $(1 \rightarrow 3)$-BG of fungal cell wall, TLR- 4 could be stimulated by LPS from Gram-negative bacterial cell wall, DAMPs or free histone DNA (from NETosis of other neutrophils).

was higher than BG activation as demonstrated by DAPI and MPO-NE co-staining, but not dsDNA (Fig. 4a-d). Because (i), respectively, and Syk and NFKB are common downstream mediators of TLR4 and dectin-1, the receptors of LPS and BG, respectively $[24,41]$, and (ii) LPS and BG induce energy alteration in several cells [25, 34, 42] that might be associated with NETosis [43], these factors are evaluated. Indeed, LPS + BG up-regulated $S y k$ and $N F \kappa B$ expression when compared with the activation by LPS or BG alone (nondifference between the stimulation by LPS vs. BG) (Fig. 5a, b). Despite a limited number of mitochondria in neutrophils [43], LPS + BG reduced mitochondrial function (oxygen consumption rate) as indicated by a reduction of maximal respiration in extracellular flux analysis (Fig. 5c-e). Meanwhile, there was no effect of LPS and/or BG on glycolysis activity of neutrophils (Fig. 5c-e).

Additionally, the importance of dectin-1 for the additive effect of BG on LPS activation was demonstrated through the inhibitory activity of dectin-1 inhibitor on 
NETs formation as indicated by the reduction of dsDNA, PAD4 expression, and NETs formation using DAPI and co-staining of MPO and NE (Fig. 6a-e). Hence, the enhanced severity of systemic inflammation in Candida-administered renal I/R mice over non-Candida mice (Fig. 13) might be due to uremia-induced gut translocation of LPS and BG (Fig. $1 \mathrm{~h}-\mathrm{j}$ ) with an additive effect of LPS plus BG on TLR4 and dectin-1 through Syk and NFkB signaling as demonstrated in a picture of working hypothesis (Fig. 7). The previously known crosstalk between TLR4 and dectin-1 $[22,44,45]$ might be responsible for the additive effect of BG on LPS-induced NETosis. The different abundance of gut fungi between humans and mice in several mouse models should be concerned. More studies on the influence of gut fungi in AKI are interesting.

\section{Discussion}

In comparison with non-Candida, $24 \mathrm{~h}$ renal-I/R in Candida-administered mice caused prominent NETs (in peripheral blood neutrophils and in glomeruli) with systemic inflammation through the profound gut translocation of LPS and BG.

\section{Gut Translocation of Pathogen Molecules and}

NETosis in Candida-Administered Renal I/R Mice

The increased serum BG (beta-glucanemia) in uremic patients which is associated with the severity of uremia (uremia-induced inflammation) [46] and beta-glucanemia-induced inflammation might partly be responsible for systemic inflammation. Because BG is a major molecule of fungal cell wall, beta-glucanemia in patients with uremia might be due to gut translocation of BG from fungi in fecal contents. Here, the impact of gut fungi on renal $\mathrm{I} / \mathrm{R}$ is examined using Candida gavage mice because (i) there is a lower abundance of fungi in mouse guts than the human intestines [3, 4]; (ii) the presence of Candida in gut enhances BG level in serum [7, 10,34, 47, 48]; and (iii) serum BG might facilitate NETosis [21]. Accordingly, oral Candida administration was required to raise the quantity of fungi to the level that fungal culture in mouse feces could be detected. On the other hand, the restoration of renal blood flow after an acute ischemic insult inevitably worsens renal injury from inflammatory processes and several program cell deaths [49]. Although apoptosis, necrosis, and necroptosis in renal parenchymal cells following ischemia are well-known $[14,15]$, the program cell death of many immune cells in the kidneys during the reactions against renal cell death [11-13] is also significant as an early step in the wound healing process [50]. Likewise, TLR-4 activation by DAMPs after renal$\mathrm{I} / \mathrm{R}$ causes significant apoptosis in renal cells and accumulated immune cells, especially neutrophils and macrophages [51-54]. Among innate immune cells, neutrophils are the most prominent cells in blood circulation and rapidly transmigrate into the injured organs, especially at the acute phase of the injury [55]. Indeed, neutrophil accumulation in renal interstitial area, glomeruli, and in urine sediments was demonstrated at $24 \mathrm{~h}$ post renal-I/R, regardless of Candida administration, that might be responsible for excessive acute inflammation, vascular permeability defect, and further loss of kidney function, referred to as "neutrophil-induced organ damage" [55]. Neutrophils in these extremely stress microenvironments from renal I/R with a high level of DAMPs, are further processed onto NETosis (cell death after NETs formation) through DAMPs-activated TLR-4 [56-58]. Although NETs are one of the important neutrophilic responses against DAMPs (either from infection or noninfection) that could induce beneficial or harmful inflammation [59], too profound NETosis worsen renal injury after I/R as indicated by increased proteinuria in Candida I/R mice when compared with non-Candida I/R mice.

Despite a well-known neutrophil-accumulation after renal I/R injury [60], NETs formation was limited only in glomeruli (causing proteinuria) but not at tubulointerstitial area. Because the renal injury score depends not only on glomerular lesion but also tubulointerstitial damage, there was nondifference renal injury score between renal I/R mice with versus without Candida administration. Likewise, the lack of difference in Scr between Candida versus non-Candida I/R mice might be due to the limitations of Scr as a kidney injury biomarker, which takes time to accumulate in serum $[61,62]$. Additionally, NETs could not be found in kidneys and extra-renal organs (liver and lung) at $6 \mathrm{~h}$ post-I/R, the time point with the most prominent lung injury $[63,64]$. Extra-renal NETs could be detected after the time-point of maximal kidney damage following renal I/R injury since the transfer of DAMPs from the necrotic kidney to other organs for NETs activation could take time [40], and NETosis is only evident in the lung at $24 \mathrm{~h}$ after renal I/R [65]. Furthermore, NETs are demonstrated in the lung but not in the liver at $24 \mathrm{~h}$ post renal I/R [65] implying the different reaction between hepatocytes and lung parenchymal cells (possibly be associated with hepatocyte detoxification property) $[66,67]$. The prominent cell deaths of neutrophils, especially NETosis, facilitate further renal injury and also induce injury in several remote organs, partly through 
thrombosis induction from free extracellular DNA and inflammation from NETs formation [68, 69]. Likewise, NETosis enhances renal tubular necrosis $[16,70,71]$ and pretreatment of renal-I/R with NETs inhibitors improves kidney injury [40]. On the other hand, NETs formation is also inducible by LPS and BG which are major cell wall components of Gram-negative bacteria and fungi, the most and second most abundant organisms in intestine, respectively [2]. Although fecal fungi could not be directly detected by culture, BG could be detected in mouse feces because of (i) some nonprominent fungi, which could be detectable by the more sensitive detection methods (gene expression or fecal microbiome analysis) [72], and (ii) BG from the mouse chow components (callose; plant BG) [73].

Due to the well-known translocation of LPS and BG from the gut into the bloodstream as a result of uremia (or renal I/R)-induced gut permeability defect (gut leakage) $[10,74]$, both LPS and BG might promote NETs formation from renal-I/R. The serum level of BG was elevated only in Candida-administered renal I/R mice but not in Candida sham mice, suggesting a role for the healthy intestinal barrier to prevent gut translocation of BG. On the other hand, serum BG in Candida-administered renal I/R mice was higher than non-Candida renal-I/R mice, implying an influence of gut fungi in renal $I / R$ mouse model. Furthermore, NETosis, both in peripheral blood neutrophils and in kidneys, of Candida-administered renal-I/R mice was more prominent in non-Candida I/R mice supporting an influence of the increased serum $B G$ from the escalated BG in gut contents due to Candida gavage. Although Candida gavage did not increase endotoxin level in intestines, Candida administration enhanced serum LPS, indicating the role of gut fungi in gut leakage facilitation. The increase in both LPS and BG in serum amplified NETosis and systemic inflammation which are well-known worsening factors of AKI and chronic kidney disease progression [32].

\section{An Additive Effect of BG on LPS-Induced NETs}

Formation, a Possible Impact of Syk Signaling and the Cell Energy Status

Because of the simultaneous presence of LPS and BG in serum of renal I/R mice and the property of NETs induction through TLR-4 and dectin- 1 activation $[75,76]$, an additive effect of LPS plus BG (LPS + BG) on NETosis is possible. As such, LPS + BG more prominently induced NETs than LPS or BG alone that was possibly mediated through Syk and $\mathrm{NF \kappa B}$, the shared downstream signaling of both TLR- 4 and dectin-1 $[24,25]$, potentially with the TLR-4 and dectin-1 cross link $[22,23]$. Here, the activity of neutrophil mitochondria (maximal respiratory capacity) was lower in LPS + BG activated neutrophils than in LPS or BG activated neutrophils; however, the mitochondrial activity of LPS or BG activated neutrophils was not different from the control. Interestingly, only LPS + BG activation, but not each molecule alone, was powerful enough to exhaust the cell's energy reserve that was used for NETs formation, resulting in a reduced ability to raise maximal respiration. On the other hand, LPS and/or BG did not alter glycolysis capacity of neutrophils. Additionally, the simultaneously activation of TLR- 4 and dectin- 1 and the cross link between these receptors might be necessary for the enhanced NETs formation as a dectin-1 inhibitor blocked NETs formation after LPS + BG activation.

Hence, the working hypothesis from all experiments is presented in Figure 7 which demonstrates the activation on several important processes of NETosis activation pathways, including TLR-4 stimulation by LPS (from uremia-induced gut translocation), DAMPs (from renalI/R) and free histone DNA (from NETosis of other neutrophils) [77] together with dectin-1 activation by BG (from gut leakage), with the cross link of both receptors (TLR-4 and dectin-1) $[22,23]$. After that, the descending signaling through Syk and NFKB (the shared downstream signals of TLR- 4 and dectin-1) activate NOX2 dependent NETs by the activation on PAD4, MPO, and NE as previously published [78-80]. Because (i) Syk is a common downstream of several NETs inducible pathways, including dectin- 1 and TLR-4 [78, 81-83], and (ii) Syk inhibitors are clinically available [84-88] with NETosis blocking activity [89]. Syk inhibitor might be a useful drug for the prevention of renal injury in patients. Future studies are of interest.

In conclusion, there was a more prominent NETs in Candida-administered renal I/R mice compared with non-Candida group due to gut permeability defect-induced gut translocation of pathogen molecules that facilitated TLR-4/dectin-1 cross link. The higher NETs in Candida-administered renal I/R mice might be more resemblance to patients with AKI, at least in term of the presence of fungi in feces, that caused more severe renal NETs and systemic inflammation then the non-Candida renal I/R model.

\section{Acknowledgments}

A.L. is under Translational Research in Inflammation and Immunology Research Unit (TRIRU), Department of Microbiology, Chulalongkorn University, Bangkok, Thailand. 


\section{Statement of Ethics}

The animal study protocol, following the National Institutes of Health (NIH), was approved by the Faculty of Medicine, Chulalongkorn University, Bangkok, Thailand, approval number [SST 022/2563]. Heparinized blood was collected from healthy donors under an approved protocol by the Ethical Institutional Review Board, Faculty of Medicine, Chulalongkorn University, approval number [IRB No. 130/63], according to the Declaration of Helsinki, with written informed consent from the participants.

\section{Conflict of Interest Statement}

The authors declare that the research was conducted in the absence of any commercial or financial relationships that could be construed as a potential conflict of interest.

\section{Funding Sources}

This research is supported by CU_FRB65_hea(33)_040_30_21, and National Research Council of Thailand (Grant No. NRCT5RGJ63001) and (NRCT-N41A640076) with NSRF via the Program Management Unit for Human Resources \& Institutional Development, Research and Innovation.

\section{Author Contributions}

The followings are the authors' contribution: conceptualization, A.L. and S.S.; methodology, A.L., S.S. and W.S.; software, A.L., S.S., W.S., and C.P.D.; validation, S.S., A.L., P.V., and D.C.; formal analysis, S.S., W.S., and A.L.; investigation, S.S., W.S., C.P.D., P.V., D.C., and A.L.; resources, A.L. and D.C.; data curation, A.L. and S.S.; writing - original draft preparation, A.L.; writing - review and editing, S.S., D.C., and A.L.; visualization, S.S. and A.L.; supervision, A.L.; project administration, S.S. and A.L.; funding acquisition, D.C. and A.L. All authors have read and agreed to the published version of the manuscript.

\section{Data Availability Statement}

Some datasets presented in this study can be found in online repositories at the article/online supplementary material. Other raw data supporting the conclusions of this article will be made available by the authors, without undue reservation, to any qualified researcher.

\section{References}

1 Jiao Y, Wu L, Huntington ND, Zhang X. Crosstalk between gut microbiota and innate immunity and its implication in autoimmune diseases. Front Immunol. 2020;11:282

2 Amornphimoltham P, Yuen PST, Star RA, Leelahavanichkul A. Gut leakage of fungalderived inflammatory mediators: part of a gut-liver-kidney axis in bacterial sepsis. Dig Dis Sci. 2019 Sep;64(9):2416-28.

3 Koh AY. Murine models of Candida gastrointestinal colonization and dissemination. Eukaryot Cell. 2013 Nov;12(11):1416-22.

4 Borges FM, de Paula TO, Sarmiento MR, de Oliveira MG, Pereira ML, Toledo IV, et al. Fungal diversity of human gut microbiota among eutrophic, overweight, and obese individuals based on aerobic culture-dependent approach. Curr Microbiol. 2018;75(6):726-35.

5 Iliev ID, Leonardi I. Fungal dysbiosis: immunity and interactions at mucosal barriers. Nat Rev Immunol. 2017;17(10):635-46.

6 Panpetch W, Somboonna N, Bulan DE, Issara-Amphorn J, Worasilchai N, Finkelman $\mathrm{M}$, et al. Gastrointestinal colonization of Candida albicans increases serum $(1 \rightarrow 3)-\beta-D$ glucan, without candidemia, and worsens cecal ligation and puncture sepsis in murine model. Shock. 2018;49(1):62-70.

7 Issara-Amphorn J, Dang CP, Saisorn W, Limbutara K, Leelahavanichkul A. Candida administration in bilateral nephrectomy mice elevates serum $(1 \rightarrow 3)-\beta$-D-glucan that enhances systemic inflammation through energy augmentation in macrophages. Int $\mathrm{J}$ Mol Sci. 2021;22(9):5031.

8 Leelahavanichkul A, Somparn P, Panich T, Chancharoenthana W, Wongphom J, Pisitkun T, et al. Serum miRNA-122 in acute liver injury induced by kidney injury and sepsis in CD-1 mouse models. Hepatol Res. 2015; 45(13):1341-52.

9 Sukkummee W, Jittisak P, Wonganan P, Wittayalertpanya $\mathrm{S}$, Chariyavilaskul $\mathrm{P}$, Leelahavanichkul $A$. The prominent impairment of liver/intestinal cytochrome P450 and intestinal drug transporters in sepsis-induced acute kidney injury over acute and chronic renal ischemia, a mouse model comparison. Ren Fail. 2019;41(1):314-25.

10 Panpetch W, Kullapanich C, Dang CP, Visitchanakun P, Saisorn W, Wongphoom J, et al. Candida administration worsens uremiainduced gut leakage in bilateral nephrectomy mice, an impact of gut fungi and organismal molecules in uremia. mSystems. 2021 Jan 12; 6(1):e01187-20.

11 Bolisetty S, Agarwal A. Neutrophils in acute kidney injury: not neutral any more. Kidney Int. 2009 Apr;75(7):674-6.

12 Bonventre JV, Yang L. Cellular pathophysiology of ischemic acute kidney injury. J Clin Invest. 2011 Nov;121(11):4210-21.
13 Cho W, Song JY, Oh SW, Kim MG, Ko YS, Lee $\mathrm{HY}$, et al. Fate of neutrophils during the recovery phase of ischemia/reperfusion induced acute kidney injury. J Korean Med Sci. 2017 Oct;32(10): 1616-25.

14 Bonegio R, Lieberthal W. Role of apoptosis in the pathogenesis of acute renal failure. Curr Opin Nephrol Hypertens. 2002 May;11(3): 301-8.

15 Price PM, Hodeify R. A possible mechanism of renal cell death after ischemia/reperfusion. Kidney Int. 2012 Apr;81(8):720-1.

16 Nakazawa D, Kumar SV, Marschner J, Desai J, Holderied A, Rath L, et al. Histones and neutrophil extracellular traps enhance tubular necrosis and remote organ injury in ischemic AKI. J Am Soc Nephrol. 2017;28(6): 1753-68.

17 Jorch SK, Kubes P. An emerging role for neutrophil extracellular traps in noninfectious disease. Nat Med. 2017;23(3):279-87.

18 Rohrbach AS, Slade DJ, Thompson PR, Mowen KA. Activation of PAD4 in NET formation. Front Immunol. 2012;3:360.

19 Azzouz D, Palaniyar N. ApoNETosis: discovery of a novel form of neutrophil death with concomitant apoptosis and NETosis. Cell Death Dis. 2018 Aug 6;9(8):839.

20 Bai Y, Tong Y, Liu Y, Hu H. Self-dsDNA in the pathogenesis of systemic lupus erythematosus. Clin Exp Immunol. 2018;191(1):1-10.
Candida Worsens Neutrophil

Extracellular Traps in Renal I/R Injury
Innate Immun 2022;14:502-517

DOI: $10.1159 / 000521633$ 
21 Saithong S, Saisorn W, Visitchanakun P, SaeKhow K, Chiewchengchol D, Leelahavanich$\mathrm{kul} \mathrm{A}$. A synergy between endotoxin and $(1 \rightarrow$ 3)-beta-D-glucan enhanced neutrophil extracellular traps in candida administered dextran sulfate solution induced colitis in FcGRIIB-/- lupus mice, an impact of intestinal fungi in lupus. J Inflamm Res. 2021;14:2333.

22 Dennehy KM, Ferwerda G, Faro-Trindade I, Pyż E, Willment JA, Taylor PR, et al. Syk kinase is required for collaborative cytokine production induced through dectin-1 and toll-like receptors. Eur J Immunol. 2008; 38(2):500-6.

23 Miller YI, Choi SH, Wiesner P, Bae YS. The SYK side of TLR4: signalling mechanisms in response to LPS and minimally oxidized LDL. Br J Pharmacol. 2012 Nov; 167(5):990-9.

24 Issara-Amphorn J, Chancharoenthana W, Visitchanakun P, Leelahavanichkul A. Syk inhibitor attenuates polymicrobial sepsis in FcgRIIb-deficient lupus mouse model, the impact of lupus characteristics in sepsis. J Innate Immun. 2020;12(6):461-79.

25 Issara-Amphorn J, Somboonna N, Pisitkun P, Hirankarn N, Leelahavanichkul A. Syk inhibitor attenuates inflammation in lupus mice from FcgRIIb deficiency but not in pristane induction: the influence of lupus pathogenesis on the therapeutic effect. Lupus. 2020; 29(10):1248-62.

26 Leelahavanichkul A, Yan Q, Hu X, Eisner C, Huang Y, Chen R, et al. Angiotensin II overcomes strain-dependent resistance of rapid CKD progression in a new remnant kidney mouse model. Kidney Int. 2010 Dec;78(11): 1136-53.

27 Leelahavanichkul A, Huang Y, Hu X, Zhou H, Tsuji T, Chen R, et al. Chronic kidney disease worsens sepsis and sepsis-induced acute kidney injury by releasing High Mobility Group box protein-1. Kidney Int. 2011 Dec;80(11): 1198-211.

28 Dang CP, Leelahavanichkul A. Over-expression of miR-223 induces M2 macrophage through glycolysis alteration and attenuates LPS-induced sepsis mouse model, the cellbased therapy in sepsis. PLoS One. 2020; 15(7):e0236038.

29 Issara-Amphorn J, Surawut S, Worasilchai N, Thim-Uam A, Finkelman M, Chindamporn $A$, et al. The synergy of endotoxin and $(1 \rightarrow 3)$ - $\beta$-D-glucan, from gut translocation, worsens sepsis severity in a lupus model of Fc gamma receptor IIb-deficient mice. J Innate Immun. 2018;10(3):189-201.

30 Thim-Uam A, Surawut S, Issara-Amphorn J, Jaroonwitchawan T, Hiengrach P, Chatthanathon $\mathrm{P}$, et al. Leaky-gut enhanced lupus progression in the $\mathrm{Fc}$ gamma receptor-IIb deficient and pristane-induced mouse models of lupus. Sci Rep. 2020 Jan 21;10(1):777.

31 Visitchanakun P, Saisorn W, Wongphoom J, Chatthanathon P, Somboonna N, Svasti S, et al. Gut leakage enhances sepsis susceptibility in iron-overloaded $\beta$-thalassemia mice through macrophage hyperinflammatory re- sponses. Am J Physiol Gastrointest Liver Physiol. 2020;318(5):G966-79.

32 Amdur RL, Feldman HI, Gupta J, Yang W, Kanetsky P, Shlipak M, et al. Inflammation and progression of CKD: the CRIC Study. Clin J Am Soc Nephrol. 2016 Sep 7;11(9): 1546-56.

33 Panpetch W, Somboonna N, Bulan DE, Issara-Amphorn J, Finkelman M, Worasilchai $\mathrm{N}$, et al. Oral administration of live-or heatkilled Candida albicans worsened cecal ligation and puncture sepsis in a murine model possibly due to an increased serum $(1 \rightarrow 3)-\beta$-D-glucan. PLoS One. 2017;12(7): e0181439.

34 Panpetch W, Sawaswong V, Chanchaem P, Ondee T, Dang CP, Payungporn S, et al. Candida administration worsens cecal ligation and puncture-induced sepsis in obese mice through gut dysbiosis enhanced systemic inflammation, impact of pathogen-associated molecules from gut translocation and saturated fatty acid. Front Immunol. 2020;11: 561652.

35 Sae-KhowK, Charoensappakit A, Visitchanakun P, Saisorn W, Svasti S, Fucharoen S, et al. Pathogen-associated molecules from gut translocation enhance severity of cecal ligation and puncture sepsis in iron-overload $\beta$-thalassemia mice. J Inflamm Res. 2020;13:719.

36 Thim-Uam A, Surawut S, Issara-Amphorn J, Jaroonwitchawan T, Hiengrach P, Chatthanathon $\mathrm{P}$, et al. Leaky-gut enhanced lupus progression in the Fc gamma receptor-IIb deficient and pristane-induced mouse models of lupus. Sci Rep. 2020;10(1):1-18.

37 Dang CP, Issara-Amphorn J, Charoensappakit A, Udompornpitak K, Bhunyakarnjanarat T, Saisorn W, et al. BAM15, a mitochondrial uncoupling agent, attenuates inflammation in the LPS injection mouse model: an adjunctive anti-inflammation on macrophages and hepatocytes. J Innate Immun. 2021 Jun 1:1-17. Epub ahead of print.

38 Wagner MC, Rhodes G, Wang E, Pruthi V, Arif E, Saleem MA, et al. Ischemic injury to kidney induces glomerular podocyte effacement and dissociation of slit diaphragm proteins Neph1 and ZO-1. J Biol Chem. 2008 Dec 19;283(51):35579-89.

39 Chen Y, Lin L, Tao X, Song Y, Cui J, Wan J. The role of podocyte damage in the etiology of ischemia-reperfusion acute kidney injury and post-injury fibrosis. BMC Nephrol. 2019 Mar 28;20(1):106.

40 Nakazawa D, Kumar SV, Marschner J, Desai J, Holderied A, Rath L, et al. Histones and neutrophil extracellular traps enhance tubular necrosis and remote organ injury in ischemic AKI. J Am Soc Nephrol. 2017 Jun;28(6): 1753-68.

41 Kawai T, Akira S. Signaling to NF-kappaB by toll-like receptors. Trends Mol Med. 2007 Nov;13(11):460-9.

42 Kang P, Liu Y, Zhu H, Li S, Shi H, Chen F, et al. The effect of aspartate on the energy metabolism in the liver of weanling pigs chal- lenged with lipopolysaccharide. Eur J Nutr. 2015 Jun;54(4):581-8.

43 Rodriguez-Espinosa O, Rojas-Espinosa $\mathrm{O}$, Moreno-Altamirano MM, Lopez-Villegas EO, Sanchez-Garcia FJ. Metabolic requirements for neutrophil extracellular traps formation. Immunology. 2015 Jun;145(2):213-24.

44 Engstad CS, Engstad RE, Olsen JO, Osterud B. The effect of soluble beta-1,3-glucan and lipopolysaccharide on cytokine production and coagulation activation in whole blood. Int Immunopharmacol. 2002 Oct;2(11):1585-97.

45 Kikkert R, Bulder I, de Groot ER, Aarden LA, Finkelman MA. Potentiation of toll-like receptor-induced cytokine production by $(1 \rightarrow 3)$-beta-D-glucans: implications for the monocyte activation test. J Endotoxin Res. 2007;13(3):140-9.

46 Wong J, Zhang Y, Swift O, Finkelman M, Patidar A, Ramanarayanan S, et al. Beta-glucans in advanced CKD: role in endotoxaemia and inflammation. BMC Nephrol. 2020 Apr 6; 21(1): 118 .

47 Hiengrach P, Panpetch W, Worasilchai N, Chindamporn A, Tumwasorn S, Jaroonwitchawan T, et al. Administration of Candi$\mathrm{da}$ albicans to dextran sulfate solution treated mice causes intestinal dysbiosis, emergence and dissemination of intestinal pseudomonas aeruginosa and lethal sepsis. Shock. $2020 \mathrm{Feb}$; 53(2):189-98.

48 Panpetch W, Hiengrach P, Nilgate S, Tumwasorn S, Somboonna N, Wilantho A, et al. Additional Candida albicans administration enhances the severity of dextran sulfate solution induced colitis mouse model through leaky gut-enhanced systemic inflammation and gut-dysbiosis but attenuated by Lactobacillus rhamnosus L34. Gut Microbes. 2020;11(3): $465-80$

49 Malek M, Nematbakhsh M. Renal ischemia/ reperfusion injury; from pathophysiology to treatment. J Renal Inj Prev. 2015;4(2):20-7.

50 Tammaro A, Kers J, Scantlebery AML, Florquin S. Metabolic flexibility and innate immunity in renal ischemia reperfusion injury: the fine balance between adaptive repair and tissue degeneration. Front Immunol. 2020;11: 1346.

51 Haase R, Kirschning CJ, Sing A, Schröttner P, Fukase K, Kusumoto S, et al. A dominant role of toll-like receptor 4 in the signaling of apoptosis in bacteria-faced macrophages. J Immunol. 2003 Oct 15;171(8):4294-303.

52 Pulskens WP, Teske GJ, Butter LM, Roelofs JJ, van der Poll T, Florquin S, et al. Toll-like receptor- 4 coordinates the innate immune response of the kidney to renal ischemia/reperfusion injury. PLoS One. 2008;3(10):e3596.

53 Zhao H, Perez JS, Lu K, George AJ, Ma D. Role of toll-like receptor-4 in renal graft ischemiareperfusion injury. Am J Physiol Renal Physiol. 2014 Apr 15;306(8):F801-11.

54 Choi Y, Sim S, Park HS. Is TLR4 critical for neutrophil apoptosis in occupational asthma? Allergy Asthma Immunol Res. 2020 Jul;12(4): $560-2$. 
55 Bolisetty S, Agarwal A. Neutrophils in acute kidney injury: not neutral any more. Kidney Int. 2009;75(7):674-6.

56 Akira S. Toll receptor families: structure and function. Semin Immunol. $2004 \mathrm{Feb} ; 16(1)$ : $1-2$.

57 Clark SR, Ma AC, Tavener SA, McDonald B, Goodarzi Z, Kelly MM, et al. Platelet TLR4 activates neutrophil extracellular traps to ensnare bacteria in septic blood. Nat Med. 2007 Apr;13(4):463-9.

58 Piccinini AM, Midwood KS. DAMPening inflammation by modulating TLR signalling. Mediators Inflamm. 2010;2010:672395.

59 Kaplan MJ, Radic M. Neutrophil extracellular traps: double-edged swords of innate immunity. J Immunol. 2012 Sep 15;189(6):2689-95.

60 Liew PX. Mired in the glomeruli: witnessing live neutrophil recruitment in the kidney. Am J Physiol Cell Physiol. 2021 Aug 1;321(2): C384-93.

61 Doi K, Leelahavanichkul A, Hu X, Sidransky KL, Zhou H, Qin Y, et al. Pre-existing renal disease promotes sepsis-induced acute kidney injury and worsens outcome. Kidney Int. 2008 Oct;74(8):1017-25.

62 Eisner C, Faulhaber-Walter R, Wang Y, Leelahavanichkul A, Yuen PS, Mizel D, et al. Major contribution of tubular secretion to creatinine clearance in mice. Kidney Int. 2010 Mar;77(6):519-26.

63 Klein CL, Hoke TS, Fang WF, Altmann CJ, Douglas IS, Faubel S. Interleukin-6 mediates lung injury following ischemic acute kidney injury or bilateral nephrectomy. Kidney Int. 2008 Oct; 74(7):901-9.

64 Lie ML, White LE, Santora RJ, Park JM, Rabb $\mathrm{H}$, Hassoun HT. Lung T lymphocyte trafficking and activation during ischemic acute kidney injury. J Immunol. 2012 Sep 15;189(6): 2843-51.

65 Saisorn W, Saithong S, Phuengmaung P, Udompornpitak $\mathrm{K}$, Bhunyakarnjanarat $\mathrm{T}$, Visitchanakun P, et al. Acute kidney injury induced lupus exacerbation through the enhanced neutrophil extracellular traps (and apoptosis) in Fcgr2b deficient lupus mice with renal ischemia reperfusion injury. Front Immunol. 2021;12:669162.

66 Zhou Z, Xu MJ, Gao B. Hepatocytes: a key cell type for innate immunity. Cell Mol Immunol. 2016 May;13(3):301-15.

67 Blondet NM, Messner DJ, Kowdley KV, Murray KF. Mechanisms of hepatocyte detoxification. Physiology of the gastrointestinal tract. Elsevier; 2018. p. 981-1001.

68 Delgado-Rizo V, Martínez-Guzmán MA, Iñiguez-Gutierrez L, García-Orozco A, Alvara-
do-Navarro A, Fafutis-Morris M. Neutrophil extracellular traps and its implications in inflammation: an overview. Front Immunol. 2017;8:81.

69 Jansen MPB, Pulskens WPC, Uil M, Claessen N, Nieuwenhuizen G, Standaar D, et al. Urinary mitochondrial DNA associates with delayed graft function following renal transplantation. Nephrol Dial Transplant. 2020 Aug 1;35(8):1320-7.

70 Havasi A, Borkan SC. Apoptosis and acute kidney injury. Kidney Int. 2011 Jul;80(1):2940.

71 Dépret F, Prud'homme M, Legrand M. A role of remote organs effect in acute kidney injury outcome. Nephron. 2017;137(4):273-6.

72 Panpetch W, Somboonna N, Palasuk M, Hiengrach P, Finkelman M, Tumwasorn S, et al. Oral Candida administration in a Clostridium difficile mouse model worsens disease severity but is attenuated by Bifidobacterium. PLoS One. 2019 Jan 15;14(1):e0210798.

73 Leelahavanichkul A, Worasilchai N, Wannalerdsakun S, Jutivorakool K, Somparn P, Issara-Amphorn J, et al. Gastrointestinal leakage detected by serum $(1 \rightarrow 3)$-beta-D-glucan in mouse models and a pilot study in patients with sepsis. Shock. 2016 Nov;46(5):506-18.

74 Gong J, Noel S, Pluznick JL, Hamad ARA, Rabb H. Gut microbiota-kidney cross-talk in acute kidney injury. Semin Nephrol. 2019; 39(1):107-16. Elsevier.

75 Bachiega TF, Dias-Melicio LA, Fernandes $\mathrm{RK}$, de Almeida Balderramas $\mathrm{H}$, Rodrigues DR, Ximenes VF, et al. Participation of dectin-1 receptor on NETs release against Paracoccidioides brasiliensis: role on extracellular killing. Immunobiology. 2016 Feb;221(2): 228-35.

76 Li RHL, Ng G, Tablin F. Lipopolysaccharideinduced neutrophil extracellular trap formation in canine neutrophils is dependent on histone $\mathrm{H} 3$ citrullination by peptidylarginine deiminase. Vet Immunol Immunopathol. 2017;193-194:29-37.

77 Dong Y, Jin C, Ding Z, Zhu Y, He Q, Zhang $\mathrm{X}$, et al. TLR4 regulates ROS and autophagy to control neutrophil extracellular traps formation against Streptococcus pneumoniae in acute otitis media. Pediatr Res. 2021;89(4): 785-94.

78 Uckun FM, Qazi S. SYK as a new therapeutic target in B-cell precursor acute lymphoblastic leukemia. J Cancer Ther. 2014 Jan;5(1):12431.

79 Li RHL, Ng G, Tablin F. Lipopolysaccharideinduced neutrophil extracellular trap formation in canine neutrophils is dependent on histone $\mathrm{H} 3$ citrullination by peptidylarginine deiminase. Vet Immunol Immunopathol. 2017 Dec;193-194:29-37.

80 Hamam HJ, Khan MA, Palaniyar N. Histone acetylation promotes neutrophil extracellular trap formation. Biomolecules. 2019 Jan 18; $9(1): 32$.

81 Mócsai A, Ruland J, Tybulewicz VL. The SYK tyrosine kinase: a crucial player in diverse biological functions. Nat Rev Immunol. 2010. 10(6):387-402.

82 Elsori DH, Yakubenko VP, Roome T, Thiagarajan PS, Bhattacharjee A, Yadav SP, et al. Protein kinase $\mathrm{C} \delta$ is a critical component of Dectin-1 signaling in primary human monocytes. J Leukoc Biol. 2011 Sep;90(3): 599-611.

83 Nguyen GT, Green ER, Mecsas J. Neutrophils to the ROScue: mechanisms of NADPH oxidase activation and bacterial resistance. Front Cell Infect Microbiol. 2017;7:373.

84 Bahjat FR, Pine PR, Reitsma A, Cassafer G, Baluom M, Grillo S, et al. An orally bioavailable spleen tyrosine kinase inhibitor delays disease progression and prolongs survival in murine lupus. Arthritis Rheum. 2008 May; 58(5):1433-44.

85 Weinblatt ME, Kavanaugh A, Burgos-Vargas R, Dikranian AH, Medrano-Ramirez G, Morales-Torres JL, et al. Treatment of rheumatoid arthritis with a Syk kinase inhibitor: a twelve-week, randomized, placebo-controlled trial. Arthritis Rheum. 2008 Nov; 58(11):3309-18.

86 Deng GM, Liu L, Bahjat FR, Pine PR, Tsokos GC. Suppression of skin and kidney disease by inhibition of spleen tyrosine kinase in lupus-prone mice. Arthritis Rheum. 2010 Jul; 62(7):2086-92.

87 Ozaki N, Suzuki S, Ishida M, Harada Y, Tanaka K, Sato Y, et al. Syk-dependent signaling pathways in neutrophils and macrophages are indispensable in the pathogenesis of anti-collagen antibody-induced arthritis. Int Immunol. 2012 Sep;24(9):539-50.

88 Kitai M, Fukuda N, Ueno T, Endo $M$, Maruyama T, Abe M, et al. Effects of a spleen tyrosine kinase inhibitor on progression of the lupus nephritis in mice. J Pharmacol Sci. 2017;134(1):29-36.

89 Al-Harbi NO, Nadeem A, Ahmad SF, Alanazi MM, Aldossari AA, Alasmari F. Amelioration of sepsis-induced acute kidney injury through inhibition of inflammatory cytokines and oxidative stress in dendritic cells and neutrophils respectively in mice: role of spleen tyrosine kinase signaling. Biochimie. 2019 Mar; 158:102-10.
Candida Worsens Neutrophil

Extracellular Traps in Renal I/R Injury
J Innate Immun 2022;14:502-517

DOI: $10.1159 / 000521633$ 